\title{
What we talk about when we talk about writing: exploring how English for Academic Purposes teachers and learning developers conceptualise academic writing
}

\author{
Sharon McCulloch \\ University of Central Lancashire, UK \\ Tania Horák \\ University of Central Lancashire, UK
}

\section{Abstract}

Two main groups of staff currently provide writing support to students in British universities. These staff typically enter their roles from a range of professional backgrounds and, consequently, may hold different professional identities and understandings of what academic writing is. Although there is a body of research on teacher identity and on lecturers' conceptualisations of writing, few studies have compared the views and identities of English for Academic Purposes (EAP) teachers and learning developers. The current study set out to investigate whether these two groups perceive academic writing in similar or different ways, and why. We undertook a small-scale study, interviewing eight participants at two universities, half from a post-1992 institution and the others from a research-intensive, high-ranking university. While participants varied in their definitions of writing, common themes emerged, lying on a spectrum from an autonomous, text-based, to an academic literacies perspective on writing. To establish the influences on these perspectives, we investigated the participants' sense of identity as an academic writer, how they learned writing themselves and any influences on them from theory. Neither the EAP teachers nor the learning developers identified strongly as academic writers, despite all holding postgraduate qualifications and some having published their writing. Most reported little to no training in how to write academically themselves, and few mentioned any theoretical stance in their approach to helping students. Although some clustering around particular conceptualisations of writing was observed, we did not find strong evidence that the participants belong to two different 'tribes'. 
Keywords: English for Academic Purposes; learning developers; academic writing; identity; academic literacies.

\section{Introduction}

The reader may have spotted our 'repurposing' of the title of two well-known books, namely Haruki Murakami's What I talk about when I talk about running (2009), the title of which is borrowed from Raymond Carver's collection of short stories What we talk about when we talk about love (1992). We wish to continue in this vein of literary theft, better termed as intertextuality (Kristeva, 1980), by exploring a key question that runs through both the aforementioned books, that of whether, when discussing a commonly-used concept, we are all talking about the same thing. In our case, this is neither running nor love, but academic writing.

Our research explores the perspectives of two groups of staff who support university students with their academic writing. Both authors, having worked as EAP (English for Academic Purposes) teachers and also learning developers, were interested in the extent to which these roles reflect different understandings of academic writing. In other words, whether EAP teachers and learning developers perceive academic writing in similar or different ways and why. We suspected that the staff in these two groups typically have distinct professional backgrounds, trajectories and training, and may therefore conceptualise academic writing differently (Wingate and Tribble, 2012). Such differences would likely then be manifested in how they support emergent academic writers. We wondered whether, although they share a similar purpose to support students in academic writing, their different job roles, work location, professional identity, and other related factors may make them two different academic 'tribes' (Becher and Trowler, 2001). If that were the case, we wondered whether lessons could be learnt on both sides by gaining insights into the beliefs and practices of the other tribe. This study aimed to investigate how valid our intuition was.

\section{Background}


Writing support for students at universities in the UK generally falls into two separate strands with different aims and approaches: pre- or in-sessional teaching of EAP on the one hand, and workshops or one-to-one tutorials led by learning development staff on the other (Wingate and Tribble, 2012). These two strands of writing support typically differ in terms of the types of students they target, the ways in which the support is provided, and the associated bodies of literature that inform them. EAP and learning development may have arisen in response to different demands but increasingly the two operate simultaneously within institutions, and the boundaries between them may be somewhat blurred. For instance, learning developers may be asked to run generic workshops on elements of academic writing such as referencing that might traditionally have come under the umbrella of EAP. Likewise, EAP teachers may include in their classes aspects of academic literacies more commonly associated with learning development, such as discussions of disciplinary norms. In this sense, the pedagogies of the two groups of professionals might overlap somewhat but what is not known is the extent to which their fundamental understandings about academic writing converge or diverge. It seems likely that the two groups could benefit from a better understanding of each other's approaches and a move towards sharing best practice.

It is not unusual for the EAP strand of writing support to be aimed at international students, taught in multi-disciplinary groups by EAP teachers in a classroom setting. This teaching context and target demographic may mean that greater emphasis is placed on English as a linguistic system in the writing support they receive. EAP pedagogies have been informed by genre theory, systemic functional linguistics, and research on academic discourse (Swales, 1990; Hyland, 2004), which have shed light on aspects of academic texts such as the use of reporting verbs (Shaw, 1992) and coherence and cohesion (Halliday and Hasan, 1989). This focus on textual features has been criticised by Lillis and Scott (2007) and others for failing to take account of the diversity of writing even within a single discipline or the contested nature of practices such as citation. For instance, research has shown that lecturers in the same discipline or even the same department may not agree on appropriate use of source materials in their students' writing (Chandrasoma et al., 2004). The focus on text in much EAP teaching has also drawn criticism (Lea and Street, 1998; Prior, 1998; Lillis and Scott, 2007) for implying that becoming a 'good' academic writer is simply a matter of mastering certain linguistic 
techniques, and for tending to see writing as politically neutral, uncontroversial and divorced from its socio-cultural context.

In contrast to the 'autonomous' model of literacy with which EAP is associated (Street, 1995), in which literacy is conceived of as a set of skills that are easily and unproblematically transferable between contexts, the theoretical underpinning of learning development tends to come from an academic literacies perspective. This is associated with a 'socio-cultural' model of literacies (Gee, 1991). This model sees writing not as a set of technical skills but as a set of meaning-making practices situated within particular social contexts (Lea and Street, 1998; Barton and Hamilton, 2000). The use of 'literacies' in the plural emphasizes the diversity of communication practices (Goodfellow, 2005) that are entangled within the concept of academic writing, including power relationships and the close link between writing and identity formation (Ivanič, 1998; Haggis, 2004; Macaro and Wingate, 2004; Gourlay, 2009). Such a theoretical perspective focuses not only on writing itself and the resultant texts but also on the ideologies, values and social context surrounding academic writing and what these mean to the writer. Learning developers also differ from EAP practitioners in terms of the target students and context in which they usually work. Learning developers typically work with both 'home' and international students, often in one-to-one consultations which may enable more in-depth discussion of an individual's goals around writing.

Several studies (Leki, 1995; Leedham, 2015; Tuck, 2015) have investigated tutors' conceptualisations of academic writing but these have tended to focus on subject lecturers rather than EAP teachers or learning developers, who are largely missing from this body of literature (Ding and Bruce, 2017). One recent exception is Jacobs (2015), who interviewed both disciplinary and academic literacies lecturers in South Africa about their understandings of concepts such as academic socialisation, academic skills and academic literacies. Jacobs found that few lecturers saw their discipline as a site of contested power relations and many focused on enabling students to use grammatically correct English. However, the professional profiles and roles of 'academic literacies' lecturers in the South African context may well differ from those of EAP teachers and learning developers in the UK and it is important to understand how the views of the latter two groups may complement each other in order to maximise the affordances of each approach. Leedham (2015), for example, has suggested that EAP teachers could benefit from adopting some 
academic literacies approaches in order to extend their understanding of what makes 'good' academic writing, but to our knowledge, no studies have attempted to compare the views and approaches of these two groups of professionals directly.

Exploring these issues and reviewing the literature therefore led us to the following two research questions:

1. How do EAP teachers and learning developers conceptualise academic writing?

2. What influences their conceptualisation?

\section{Methodology}

Our study was a small-scale, exploratory study to test our initial inkling regarding the two different groups of staff discussed above.

\section{Data Collection}

We interviewed eight participants currently working at two universities in the north of England. These two institutions were chosen partly out of convenience since we had professional contacts in both, and partly to facilitate comparison of two types of university. Four participants were based at University A, a post-1992 institution (i.e. one of the group of British institutions that gained university status in 1992, having previously been a technical institute or polytechnic college offering vocational qualifications rather than degrees), with a strong widening participation agenda, attracting students who had not experienced the conventional route through the education system. According to University A's strategy, almost $18 \%$ of its full-time first degree students came from 'low participation neighbourhoods' in 2016-17 (University A, Access and Participation Plan 2019-2020). Consequently, there is a high proportion of working-class students. The other four participants were based at University $B$, a research-intensive, high-ranking university, attracting more middle-class students. According to University B's website, more than one third of its research is ranked as 'world leading', and three separate British university guides rank it among the top 10 universities in the UK. University B recruited less than $10 \%$ of its full-time first degree students from low participation neighbourhoods in 2016-17 (University B, Access and Participation Plan 2019-2020). 
The participants fell into two categories: the first included those mostly involved in teaching international students and typically having an EFL and subsequently an EAP background in their career profile. Their job titles varied from tutor to associate tutor/lecturer, and we have labelled them 'EAP teachers' for the purposes of this study. The job titles held by learning developers in the UK also vary widely, and include academic skills tutor, learning advisor, academic developer, etc. For the purposes of this study, we labelled them 'learning developers'. This applied to staff based within, or assigned to work primarily with, specific schools or faculties to provide study support for students from specific disciplinary backgrounds (e.g. engineering, medicine, humanities). Table 1 summarises the study's participants.

Table 1. Participants' job roles and institutions.

\begin{tabular}{|l|c|c|}
\hline \multirow{2}{*}{ University A (post-1992) } & EAP teachers (EAP) & Learning developers (LD) \\
\cline { 2 - 3 } & EAP1A & LD1A \\
\hline \multirow{2}{*}{$\begin{array}{l}\text { University B (research } \\
\text { intensive) }\end{array}$} & EAP2A & LD2A \\
\cline { 2 - 3 } & EAP1B & LD2B \\
\hline
\end{tabular}

As regards the participants' professional backgrounds, the EAP teachers had all started out teaching EFL (English as a Foreign Language); one had taught primarily in her home country before coming to the UK, the others had worked in various teaching posts both in the UK and abroad. EFL teaching had taken up the majority of their working lives before moving into EAP. The learning developers were more varied in their profiles. They had studied subjects such as modern languages, psychology, education and science at undergraduate level and had worked in other fields (including research, secondary- and primary-level teaching, and the public sector) before their current role. Only one had some experience of university-level teaching in their subject area (and still held this role concurrently with her LD role).

The participants were selected through purposive and convenience sampling, in that we initially approached contacts we knew in these two professions, who we knew to be working in one of the above roles. This approach was accompanied by an element of 
snowball sampling, asking our contacts to put us in touch with further potential participants in our target institutions. Potential participants were included if they were currently working in a post with primary responsibility for supporting students in academic writing. Of those approached, a total of eight were available and willing to be interviewed. All the participants were female. This was not intentional but reflected the gender balance of professionals working in the target institutions and the availability of participants at the time of the data collection.

Interviews were chosen as the most appropriate method of eliciting information about participants' own conceptualisations of academic writing, since other methods, such as questionnaires, are not amenable to collecting data about such complex matters as one's understanding of what academic writing is and one's professional identity. Moreover, Kvale's interpretation of interviews as 'inter-views' (1996), or tools for seeing into a phenomenon, is appropriate for exploratory studies such as this, where, within the framework of our research questions, we wished to look at participants' conceptualisations of writing, not look for specific features. We recognise that using a single instrument to collect data has its limitations. However, as we were interested in participants' personal viewpoints and understandings, rather than, say, their actual practices in the classroom, we did not use other methods such as observations.

All participants signed consent forms agreeing to our use of the data for research purposes and confirming that they understood that all the data would be fully anonymised. Participants were informed of the general nature of our enquiry (perceptions of academic writing) but not of the potential influence of their roles or other factors we discussed, in order to avoid bias. We later fed back preliminary findings through presentations for their professional teams, at which we discussed the study more fully with the participants. We conducted one semi-structured interview with each participant at their workplace in a quiet location where they could speak freely. Interviews were audio recorded and lasted an average of 35 minutes each (see Appendix A for the interview schedule). Each researcher interviewed half of our participant group, randomly assigned. Interview questions focused on four main areas, as follows:

- Role: We asked participants what they did on a day to day basis to see how they characterised their work. 
- Professional identity: We asked participants how they located themselves in terms of professional identity in order to gain an emic perspective on the purpose of their role.

- Definitions: As academic writing itself is a complex, contested phenomenon, we asked the participants to share their personal definition of academic writing. As discussed above, writing can be described via various paradigms and we wanted to ascertain which of these our participants most aligned to, consciously or otherwise.

- Influences: In order to understand what influenced their current approach to supporting students, we asked participants about their own experiences as an academic writer, including which genres, disciplines and writing processes they were most familiar with and how they had learnt these. We also asked about any training they had received and any theoretical concepts they drew on.

\section{Data analysis}

Each researcher listened to the audio data carefully several times. We carried out thematic coding whereby key points and concepts were identified and time stamps for these were noted systematically for easy return and retrieval. Coding was carried out independently, then compared, and instances of ambiguity or disagreement were discussed in order to reach agreement. Key episodes were then discussed and grouped into common themes. We compared our lists of themes and combined them into a single list of instances in the data, which we felt addressed each research question. We also discussed the most telling and compelling ways of talking about academic writing. We then listened once more to the interviews and agreed together the most important of these key emergent points. Having established main themes, we then listened again to our interviews to undertake negative case analysis (Marshall and Rossman, 2006), searching for data that contradicted what we felt to be our main findings..

\section{Findings and discussion}

Independent analysis of episodes in the interviews and discussion of their significance yielded a series of findings, which we felt satisfactorily addressed our research questions. These are discussed below in relation to each research question in turn. 


\section{Research question 1: how do the participants conceptualise academic writing?}

In order to establish the extent to which EAP teachers and learning developers conceptualise academic writing in the same ways, we first present some examples of the interviewees' definitions of academic writing. While participants varied in their definitions, certain common themes emerged. These conceptualisations could be seen to lie on a spectrum from, at one end, a more text-based perspective, focusing mainly on textual features such as formality and style, to, at the other end, an academic literacies perspective, focusing on writing as closely linked to one's self and personal identity.

They included the following:

- It is about formality, e.g. 'it's not jokey writing - it's formal' (LD2B) and also noted in similar terms by LD1A, LD1B, EAP2B.

- It is a specific style of writing, e.g. 'academic writing is a stylised piece of writing that is aimed at particular audiences' (LD2B) and 'it's a very particular style of writing very succinct, very precise' (LD1A).

- It is about rules and conventions, e.g. 'It's buying into the conventions of academia really, isn't it?' (LD2A) or '[it's about] knowing the rules and conventions of referencing for example' (EAP2B).

- It is about reader/audience expectations, e.g. '[it is] what I expect to read when I open an academic book' (EAP1A) or '[it is something that would] tick the boxes and fulfil criteria that would be expected' (EAP2B).

- It is about presenting arguments and ideas, e.g. 'academic writing in a UK Anglo culture is asking ostensibly students to show they can think critically I suppose and logically organise a sequence of argumentation according to Greek rhetorical forms of argumentation' (EAP1B) and 'you need to take your opinion on a subject and turn it into an academic argument by reading the experts and supporting it' (LD1A).

- It is about expressing one's own scholarly voice, e.g. 'you definitely can put your own ideas and voice across' (LD2B). 
Entirely without prompting from the interviewers, most of the participants used metaphors to talk about academic writing. One EAP teacher described academic writing as a set of components that ticks predetermined boxes:

So I suppose I break academic writing down into components, which if adhered to would produce something that looks like an academic essay. It may not be particularly insightful, but it would tick the boxes and would fulfil criteria that would be expected (EAP2B).

This metaphor characterises academic writing as a highly decontextualised product that can be evaluated in terms of a checklist of essential features. It stands alone, disconnected from disciplinary subject matter, the text's purpose and the writer's identity. Another EAP teacher at the same university described academic writing in a similar way, as a process of jumping through hoops to demonstrate competence:

I would look at the requirements of the particular department or the particular group who was assessing what that writer has to do. So I would, in a sense, define it in terms of what that writer is required to do to jump through the hoops in order to be thought a competent writer (EAP1B).

This definition of writing is, again, fairly instrumental, focusing on academic writing mainly as a means to an end. Both these comments include the concept of the writer being judged against externally-set expectations and they are similar to Casanave's (2002) notion of 'writing games' in that they foreground the rule-based and highly conventional aspects of academic writing.

One of our participants who worked as a learning developer described academic writing as learning a new language or translating:

Learning a new language is how I describe it to the students. . . I always tell them that I'm from [city], and . . I I need to translate things from academic writing into [city] so that I can understand it, get my head around it and really understand it before I can then translate it back into academic writing (LD1A). 
While academic discourse is often described as nobody's first language (Bourdieu and Passeron,1984; Hyland, 2016), in this case our participant was talking about translation in terms of issues of class, translating from a local vernacular into academic discourse, and back again. This metaphor spoke of transition of the self.

Another powerful metaphor that a learning developer used to define academic writing was as follows:

It's also like giving them the keys to a new kingdom, to say this is your introduction to the world of academia. This is how you access knowledge; this is how you create knowledge (LD2A).

This metaphor is also concerned with transition or movement from one world to another. It also echoes Lillis and Scott's (2007) characterisation of academic literacies as being potentially transformative by facilitating access to powerful knowledge.

These metaphors reveal two main conceptualisations of academic writing, one seeing it as a means of displaying one's credentials in terms of mastery of textual features and the other placing far greater emphasis on writing as a socially situated vehicle for personal development. It is worth noting that these metaphors may reflect how our participants themselves viewed academic writing, but they may also express an element of empathy with the challenges facing their students, describing academic writing from the student perspective. The latter two metaphors came from learning developers, which does, prima facie, suggest that this 'tribe' sees writing as embedded within a socio-cultural, academic literacies perspective, more than was the case for the EAP teachers. However, there were also instances in the data of the EAP tutors foregrounding the role of social context in writing, and learning developers discussing writing in terms of rules and conventions. For example, one EAP teacher, when asked to define academic writing, replied: 'I suppose I always look at it politically' (EAP1B), and one learning developer defined writing partly in terms of following conventions: 'you need to follow certain conventions and those are the conventions of academic writing' (LD2B).

Overall, we found a diversity of understandings, with most of the participants providing nuanced descriptions of academic writing, which often touched upon both textual features 
and contextual or ideological aspects of writing. Few appeared to see academic writing as any sort of monolithic entity.

Having established how our participants talked about academic writing, we discuss below the factors that may have influenced these conceptualisations.

\section{Research question 2: what influenced these views of writing?}

To investigate this question, we asked our participants about their own academic writing, how they had learned it, and which, if any, theories or concepts influenced their practice.

\section{Identifying as an academic writer}

We know that writing plays an important role in student identify formation (Haggis, 2004;

Gourlay, 2009) and that academic writing lies close to the heart of professional academics' identity (Tusting et al., 2019), so it is reasonable to assume that it might play a similar role in the professional identity of those who teach or otherwise support students to develop their academic writing. We therefore asked our participants about their own academic writing in order to explore the extent to which they saw themselves as academic writers in terms of identity or expertise and how this might influence their practice. We were rather surprised to find that most claimed to do very little or no academic writing currently. When asked, 'Do you do or have you done any academic writing?', answers included: 'No, not a sausage' (EAP2B); 'Other than my MA, no' (EAP2A); 'Not much and I'm not very good at it' (LD1B). Only two participants, both learning developers, reported being active academic writers, having published 'a couple of papers' (LD2B) and responding: 'I've done a bit' (LD2A). Most participants did not identify themselves as academic writers and tended to reject the notion of being experts. While all of our participants were qualified to Master's level and two had PhDs (LD2B and LD1A), and thus had all done what we, as researchers, consider academic writing in the past, none of them mentioned this in relation to this question, aside from the 'other than my MA' comment above. This may suggest they undervalued their own previous academic writing while they were academics-intraining, and equated academic writing with professional publication. Their stance was rather puzzling, given that academic writing of all sorts lies at the heart of their everyday working lives. 
Research demonstrates how important the publishing of scholarly work is to academics (McCulloch, 2017), including EAP teachers (Davis, 2018). Despite this, Davis (2018) has found that EAP teachers face various obstacles to publishing, including lack of time and institutional support. Indeed, several of our participants (EAP2A, EAP2B and LD2B) mentioned lacking time but wanting to do more academic writing. Similar issues likely face many learning developers too, given that they are frequently positioned as 'professional services' staff rather than academics (Hilsdon, 2010). It may therefore be that although academic writing was important in the work of our participants, unless this was published in disciplinary journals, they did not feel ready to claim the identity of an 'academic writer'. Only two of our participants (LD2A and LD2B) had published their writing and this might account for the reluctance of the others to see themselves as expert writers.

\section{Learning writing}

We asked participants about their own experience of learning academic writing since this is likely to influence their views and approaches to supporting their students. For many of our participants, their experience of doing an MA had been a turning point in their understanding of academic writing and its wider purpose. Some (EAP2B and LD2B) mentioned the guidance of a specific mentor or supervisor who gave them feedback on their writing. Others talked about 'picking it up' or learning from colleagues 'through my job' (EAP1B) and some claimed not to have learned how to do academic writing. Most participants' views on how they learned academic writing fit with an academic socialisation understanding of literacy as something learned informally, through a form of apprenticeship (Lea and Street, 1998). In this sense our participants felt that they learned mainly through the process of writing as novices, rather than through any formal 'teaching' or study. This style of learning and the lack of formal qualification in writing could possibly have been a contributing factor to the lack of a clear identity as a writer or an 'expert' in academic writing. Our participants' writing identities may be somewhat rhizomic, in the sense discussed by Deleuze and Guattari (1987), in that they may be characterised by multiple interlinked points rather than having a clear main root and direction of growth. Writing identities may be subject to change, shaped by the various roles our participants play, relationships they form and communities of practice they move in (French, 2019).

\section{Lack of influence from theory}


Lastly, we also explored the extent to which participants drew on theories and concepts in the fields of learning, EAP, literacy or literacies, in the hope of ascertaining whether they aligned themselves to any particular schools of thought. However, very few mentioned any theoretical stances at all, even when asked directly. This might suggest, in support of Ding and Bruce (2017), that their current practice has developed more through experiential learning (Green and Powell, 2005) than through the direct influence of theoretical knowledge or training. It is true that, while the majority of EAP teachers have MAs in TESOL, applied linguistics or education, relatively few have undertaken specific EAPoriented training through which an EAP-specific theoretical underpinning to their practice might have been developed (Fitzpatrick et al., 2019). Instead, many take up their first EAP posts after completing qualifications and gaining experience in general TEFL (Teaching English as a Foreign Language) (Campion, 2016). Likewise, there is no single route into the field of learning development, nor an established pre-entry qualification (Murray and Glass, 2010), which might enable practitioners to draw on a common set of theories.

Without doubt, although there has been a proliferation of research in the field of EAP and learning development over the past 20 years or so (Wingate and Tribble, 2012), there remains, according to Ding and Bruce (2017, p.118), something of a 'schism' between the research base and the day-to-day practice of EAP professionals. It may therefore be that our participants did not engage a great deal with research literature or theory. Those theories that our participants did mention sat within a socio-cultural paradigm, a specific example being Biggs's constructive alignment (1996), rather than EAP, academic literacies or writing theories per se.

\section{The perceived relevance of socio-cultural context}

A further factor that emerged as shaping participants' conceptualisations of academic writing was the perceived interrelationship between text and context. All the participants talked about text but only some also discussed context, for example seeing academic writing as a vehicle for instigating change by developing critical thinking.

\section{Two EAP teachers (EAP1A and EAP2A) talked about their approach to supporting} students with writing mainly in terms of the mechanics of writing, such as teaching classic essay structure, developing appropriate vocabulary and understanding genre or enabling specific, short-term gains in the form of improved grades on essays, through improving 
punctuation and sentence structure. While we cannot discount the possibility that they also saw social context as important to writing, but happened not to foreground this aspect of their work, these participants' focus on textual and linguistic elements of writing does suggest an understanding of academic writing as in line with a relatively autonomous model of literacy (Street, 1995).

In contrast, some participants could not dissociate academic writing from aspects of the socio-cultural context such as students' lives, aims and barriers to their learning. When asked how they went about supporting students with academic writing, some participants (LD1A and LD1B) talked about helping them to develop their cultural capital (Bourdieu, 1986), confidence and life chances. This suggests that, although they did not draw explicitly on theories relating to the role of identity and power relations in academic writing, they nevertheless saw writing as embedded within, and shaped by, social forces. In a similar vein, two participants, both learning developers (LD1A and LD2A), explicitly talked about their understanding of writing as highly situated, and about the transformational power of education discussed above. It is notable that they were learning developers at the post-1992 institution, which, as discussed earlier, has a pronounced widening participation agenda, with many students arriving via non-traditional routes, arguably without the cultural capital of most students at the higher-ranking university. Working with such students may lead learning developers to appreciate the effects of one's wider sociopolitical context on one's writing. In this sense, some participants saw greater complexity in academic writing than others, taking account of wider contextual issues and characterising these as relevant factors in supporting students with their writing.

Returning to our initial feeling that EAP teachers and learning developers might belong to different tribes, we drew together the data from the four sub-themes discussed above, namely the participants' conceptualisations of writing, the way they had learned to write themselves, the theoretical frameworks they drew on in discussing writing, and the extent to which they saw the socio-cultural context as relevant to writing. This enabled us to look at each participant's interview as a whole to gauge the extent to which their comments overall reflected a broadly autonomous view of literacy (Street, 1995) as a mainly textual, de-contextualised phenomenon, or a broadly socio-cultural view of academic writing as socially-embedded and highly contextualised. If a participant foregrounded features of text such as rules of essay structure, conventions, and academic style in their interview as a 
whole, we placed them at the 'autonomous' end of the spectrum shown in Figure 1, and if they talked more about class, identity, voice, and power, for example, we placed them at the other end.

\section{Figure 1. Participants placed on a spectrum according to how strongly their comments reflected an autonomous or socio-cultural perspective on academic writing.}

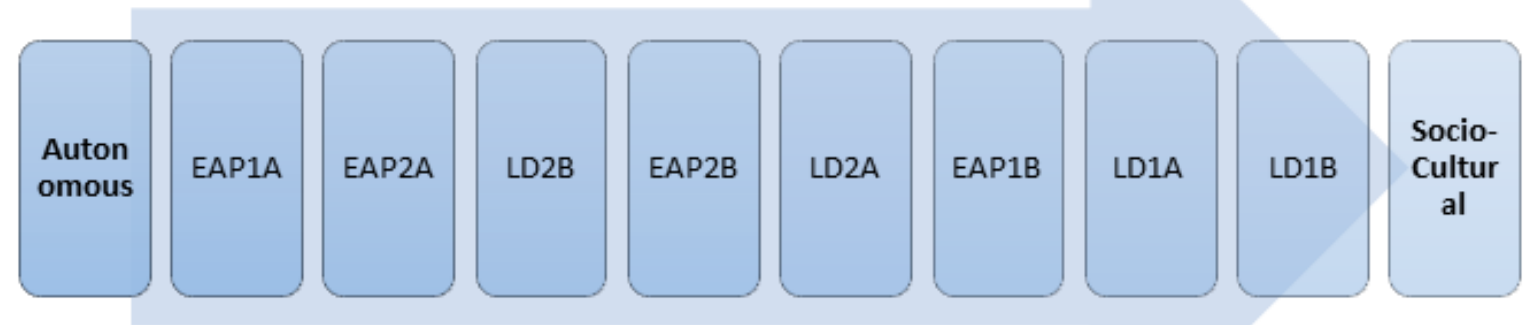

Figure 1 shows that, while there is some clustering of EAP teachers at the 'autonomous' end of the scale and learning developers at the 'socio-cultural' end, the pattern is not completely linear. In other words, in this small group of participants, the two professional groups do not fall clearly into two different 'tribes' in terms of their overall conceptualisation of academic writing. However, the two 'extreme' ends of the spectrum in Figure 1 do provide some evidence of different ways of thinking about academic writing. The two participants who talked least about the issues around the socio-cultural context of writing were EAP tutors, while the two who saw these issues as most relevant to academic writing were both learning developers; but in the middle, a diversity of views was present.

As discussed above, the two universities at which our participants worked differed in terms of the type of students they attracted. As already stated, University A was a post-1992 institution with a higher proportion of 'widening participation' and working-class students. Conversely, University $\mathrm{B}$, with its higher ranking in league tables, had a generally more middle-class intake. It is possible that understandings of academic writing might be shaped in part by the types of students and institutional context in which one works. For example, 
those working with students from a widening participation background might see issues of class and power as more relevant, so might tend to hold views of writing more informed by an academic literacies paradigm than those at University B. If this were the case, we would expect participants from University B to cluster around one end of the spectrum but Figure 1 above shows that there is no clear clustering of participants based on their employing institution.

\section{Conclusions}

In reporting our results, we are mindful of the small sample in this study and must be cautious in drawing conclusions and suggesting generalisability to other cases. However, we have no reason to suspect atypicality (Mason, 2002) of our participants, other than the lack of male participants, and can thus assume a certain degree of transferability to other staff in similar positions.

Overall, the findings do not provide strong evidence that the participants make up two different tribes. EAP teachers and learning developers in this sample talked about writing in relatively similar ways, usually discussing both textual features and socio-cultural factors, albeit to different extents. Neither group drew heavily on the scholarly literature on academic writing or saw theory as a significant influence on their practice. Instead, most described the experience of learning to write as students with the support of a supervisor, tutor or mentor as the biggest influence on their understanding of academic writing.

One of the most surprising findings was that neither the EAP teachers nor the learning developers identified strongly as academic writers or experts in writing, despite all holding postgraduate qualifications and some having published their writing in peer-reviewed journals, even though the nature of their posts meant they discussed academic writing in all forms, not just professional publication, on a daily basis. 'An academic writer' seemed to have a rather specific meaning for them. It may be that, as French (2019) suggests, greater critical awareness of the various ways that their own writing experiences inform their identity would benefit both EAP teachers and learning developers in terms of claiming their disciplinary space. 
A larger sample would be needed to draw firm conclusions, but it is possible that the mixed professional experience of this group of participants may have influenced their beliefs about writing. For example, several participants had worked in both EAP teaching and learning development roles in their career, which might have led them to see writing within a broader context. Future studies could include more EAP teachers with an EFL background but no learning development experience, or EAP teachers working for private providers attached to universities, to explore whether these factors might also influence their views.

Beyond the experience of the individual, other explanations for the finding that these two groups of professionals do not constitute two different tribes might lie in the changing nature of higher education in the UK. Increased internationalisation and massification (Tusting et al., 2019) may mean that distinctions between the needs of international and home students are becoming less clear, leading to a blurring of the boundaries between the roles of staff supporting them.

By shedding light on what we talk about when we talk about academic writing, we can raise awareness among staff who support academic writing about the range of conceptualisations that exist, all of which may be valid for the range of student circumstances that pertain in universities today. Enabling staff to locate their practice within this complexity may also facilitate the sharing of good practice. For example, EAP teachers may benefit from the greater awareness of how students' lives as a whole influence their writing, and learning developers may benefit from the type of meta-linguistic awareness that EAP teachers typically have to enable them to talk about issues that may pertain to students' writing such as the use of cohesive devices or reporting verbs. Secondly, a re-evaluation of professional identities in the field, a process kick-started by the November 2018 joint conference by BALEAP and ALDinHE, the professional organisations of EAP teachers and learning developers respectively, may facilitate greater awareness of the range of ways in which one can be a professional academic writer, and the range of expertise these two groups bring to their field.

Future studies investigating these issues with larger populations at a wider range of research sites would of course be useful, as would an examination not only of the two 
professional groups' conceptualisations of academic writing, but also their practices, both in supporting students and in their own writing.

\section{References}

Barton, D. and Hamilton, M. (2000) 'Literacy practices', in Barton, D. Hamilton, M. and Ivanič, R. (eds) Situated literacies. London and New York: Routledge, pp.7-15.

Becher, T. and Trowler, P. (2001) Academic tribes and territories: Intellectual enquiry and the culture of disciplines. $2^{\text {nd }}$ edn. Buckingham: Open University Press.

Biggs, J. (1996) 'Enhancing teaching though constructive alignment', Higher Education, 32(3), pp. 347-364.

Bourdieu, P. (1986) 'The forms of capital', in Richardson, J. (ed) Handbook of theory and research for the sociology of education. Westport, CT: Greenwood, pp.46-58.

Bourdieu, P. and Passeron, J.C. (1994) 'Introduction: Language and relationship to language in the teaching situation', in Bourdieu, P., Passeron, J.C. and de Saint Martin M. (eds.) Academic Discourse: Linguistic misunderstanding and professorial power. Cambridge: Polity, pp.1-34.

Campion, G. C. (2016) “The learning never ends”: Exploring teachers' views on the transition from general English to EAP', Journal of English for Academic Purposes, 23, pp.59-70.

Carver, R. (1992) What we talk about, when we talk about love. $4^{\text {th }}$ edn. London: Vintage Books.

Casanave, C. (2002) Writing games: Multicultural case studies of academic literacy practices in higher education. Abingdon: Routledge.

Chandrasoma, R., Thompson, C. and Pennycook, A. (2004) 'Beyond plagiarism:

Transgressive and nontransgressive intertextuality', Journal of Language, Identity 
and Education, 3(3), pp.171-193. Available at:

https://doi.org/10.1207/s15327701jlie0303 1 (Accessed:16 May 2019).

Davis, M. (2018) “'If you don't write yourself, on what grounds can you offer advice about writing to others?" The importance and multiple impacts of publishing by teachers of academic writing', Journal of Academic Writing, 8(2), pp.4-35. Available at: https://doi.org/10.18552/joaw.v8i2.459 (Accessed: 29 May 2019).

Deleuze, G and Guattari, F. (1987) A Thousand Plateaus: Capitalism and Schizophrenia. Minneapolis: University of Minnesota Press.

Ding, A. and Bruce, I. (2017) The English for academic purposes practitioner: Operating on the edge of academia. Basingstoke, UK: Palgrave Macmillan.

Fitzpatrick, D., Costley, T. and Tavakoli, P. (2019) 'What do we mean by EAP teachers? Reflections on practice, pedagogy and professional development'. Paper presented at the BALEAP annual conference, Leeds University, England, 12-14 April 2019. Available at: https://www.baleap.org/event/baleap-2019-leeds/damian-fitzpatrickand-tracey-costley-what-do-we-mean-by-eap-teachers (Accessed: 16 May 2019).

French, A. (2019) 'Academic writing as identity-work in higher education: Forming a "professional writing habitus"', Studies in Higher Education, Available at: https://doi.org/10.1080/03075079.2019.1572735 (Accessed: 6 April 2019).

Gee, J. (1991) 'Socio-cultural approaches to literacy (literacies)'. Annual Review of Applied Linguistics, 12, pp.31-48.

Goodfellow, R. (2005) 'Academic literacies and e-learning: A critical approach to writing in the online university', International Journal of Educational Research, 43(7-8), pp. 481-494. Available at: https://doi.org/10.1016/j.ijer.2006.07.005 (Accessed: 22 April 2019).

Gourlay, L. (2009) 'Threshold practices: Becoming a student through academic literacies', London Review of Education 7(2), pp.181-192. 
Green, H. and Powell, S. (2005) Doctoral study in contemporary higher education. Maidenhead: SRHE and Open University Press.

Haggis, T. (2004) 'Meaning, identity and "motivation": Expanding what matters in understanding learning in higher education?', Studies in Higher Education, 29(3), pp. 335-352. Available at: https://doi.org/10.1080/03075070410001682538 (Accessed: 22 April 2019).

Halliday, M. K. and Hasan, R. (1989) Language context and text: Aspects of language in a social semiotic perspective. $2^{\text {nd }}$ edn. Oxford: Oxford University Press.

Hilsdon, J. (2010) 'What is learning development?' in Hartley, P., Hilsdon, J., Keenen, C., Sinfield, S. and Verity, M. (eds.) Learning Development in Higher Education. Basingstoke: Palgrave Macmillan, pp.13-27.

Hyland, K. (2004) Disciplinary discourses: Social interactions in academic writing. Michigan: University of Michigan.

Hyland, K. (2016) Academic publishing: Issues and challenges in the construction of knowledge. Oxford: Oxford University Press.

Ivanič, R. (1998) Writing and identity: The discoursal construction of identity in academic writing. Amsterdam: John Benjamins.

Jacobs, C. (2015) 'Opening up the curriculum: moving from the normative to the transformative in teachers' understandings of disciplinary literacy practices', in Lillis, T., Harrington, K., Lea, M. and Mitchell, S. (eds.) Working with academic literacies: Case studies towards transformative practice. Fort Collins, Colorado: The WAC Clearinghouse and Parlor Press, pp.131-141.

Kristeva, J. (1980) Desire in language: A semiotic approach to literature and art. New York: Columbia University Press. 
Kvale, S. (1996) InterViews: An introduction to qualitative research interviewing. Thousand Oaks, CA: Sage Publications.

Lea, M. R. and Street, B. V. (1998) 'Student writing in higher education: An academic literacies approach', Studies in Higher Education, 23(2), pp.157-172. Available at: https://doi.org/10.1080/03075079812331380364 (Accessed: 22 April 2019).

Leedham, M. (2015) 'Learning from lecturers: What disciplinary practice can teach us about "good” student writing', in Lillis, T., Harrington, K., Lea, M. and Mitchell, S. (eds.) Working with academic literacies: Case studies towards transformative practice. Fort Collins, Colorado: The WAC Clearinghouse and Parlor Press, pp.163-174.

Leki, I. (1995) 'Coping strategies of ESL students in writing tasks across the curriculum', TESOL Quarterly, 27(4), pp. 235-260.

Lillis, T. M. and Scott, M. (2007) 'Defining academic literacies research: Issues of epistemology, ideology and strategy', Journal of Applied Linguistics, 4(1), pp.5-32.

Macaro, E. and Wingate, U. (2004) 'From sixth form to university: Motivation and transition among high achieving state-school language students', Oxford Review of Education, 30(4), pp. 467-488. Available at: https://doi.org/10.1080/0305498042000303964 (Accessed: 30 May 2019).

Marshall, C. and Rossman, G. B. (2006) Designing qualitative research. $4^{\text {th }}$ edn. London: Sage.

Mason, J. (2002) Qualitative researching. London: Sage.

McCulloch, S. (2017) 'Hobson's choice: The effects of research evaluation on academics' writing practices in England', Aslib Journal of Information Management 69(5), pp. 503-515. Available at: https://doi.org/10.1108/AJIM-12-2016-0216 (Accessed: 14 April 2019 ). 
Murakami, H. (2009) What I talk about when I talk about running. London: Vintage.

Murray, L. and Glass, B. (2010) 'Learning development in higher education: community of practice or profession?' in Hartley, P., Hilsdon, J., Keenen, C., Sinfield, S. and Verity, M. (eds.) Learning Development in Higher Education. Basingstoke: Palgrave Macmillan, pp.28-38.

Prior, P. (1998) Writing/disciplinarity: A sociohistoric account of literate activity in the academy. Mahwah, MJ: Lawrence Erlbaum.

Shaw, P. (1992) 'Reasons for the correlation of voice, tense, and sentence function in reporting verbs', Applied Linguistics, 13(3), pp.302-319.

Street, B. (1995) Social literacies: Critical approaches to literacy development, ethnography and education. London: Longman.

Swales, J. M. (1990) Genre analysis: English in academic and research settings. Cambridge: Cambridge University Press.

Tuck, J. (2015) '“Doing something that's really important”: Meaningful engagement as a resource for teachers' transformative work with student writers in the disciplines', in Lillis, T., Harrington, K., Lea, M. and Mitchell, S. (eds.) Working with academic literacies: Case studies towards transformative practice. Fort Collins, Colorado: The WAC Clearinghouse and Parlor Press, pp.195-204.

Tusting, K., McCulloch, S., Bhatt, I., Hamilton, M. and Barton, D. (2019) Academics writing: The dynamics of knowledge creation. Abingdon: Routledge.

Wingate, U. and Tribble, C. (2012) 'The best of both worlds? Towards an English for academic purposes writing pedagogy', Studies in Higher Education, 37(4), pp. 481495. Available at: https://doi.org/10.1080/03075079.2010.525630 (Accessed: 9 October 2018). 


\section{Author details}

Sharon McCulloch is a senior lecturer at UCLan, where she leads the university's presessional and study overseas programmes. She has previously worked as both an EAP tutor and a learning developer. Her research interests include academic literacies, EAP, and academic and professional writing.

Tania Horák is a senior lecturer at UCLan (UK) teaching on EFL teacher training programmes and is currently course leader of MA in TESOL and Applied Linguistics. She has previously worked in ELT in the UK, the Czech Republic, Bangladesh and Lithuania. Her research interests lie in academic writing and also foreign language testing. 


\section{Appendix: Interview schedule}

\section{Participant's role}

What's your job title? What do you do?

What does your typical day look like?

\section{Participant's understanding of writing}

How would you personally define academic writing?

Do you - or have you done - do any academic writing yourself?

If so, what sort? (genres, disciplines, processes, etc.)

How did you learn how to do academic writing? What influenced you?

\section{Participants' experience / background}

What's your (professional) background?

What qualifications/training did you have to prepare you for your role? If any.

Does that inform what you do with your students, and if so, how?

What else does?

Does your own experience of writing and learning to write inform what you do with your students, and if so, how?

\section{Theories drawn on}

Are there any particular theories/schools of thought/concepts you draw on to inform your work on academic writing?

Can you give an example of how you use these in your professional practice?

\section{Close}

Is there anything you thought l'd ask which I haven't?

Is there anything else you think might be relevant to this study?

Do you have any other questions? 